\title{
An expansible aortic ring for a physiological approach to conservative aortic valve surgery
}

\author{
Emmanuel Lansac, MD, PhD, ${ }^{\mathrm{a}, \mathrm{b}}$ Isabelle Di Centa, $\mathrm{MD},{ }^{\mathrm{c}}$ François Raoux, MD, ${ }^{\mathrm{d}}$ Neil Bulman-Fleming, \\ Adrian Ranga ${ }^{\mathrm{e}}$ Aicha Abed, MSc, ${ }^{\mathrm{a}, \mathrm{f}}$ Maguette Ba, MD, ${ }^{\mathrm{a}}$ Anthony Paolitto, ${ }^{\mathrm{e}}$ Didier Letourneur, PhD, ${ }^{\mathrm{a}, \mathrm{f}}$ and \\ Anne Meddahi-Pellé, MD, $\mathrm{PhD}^{\mathrm{a}, \mathrm{g}}$
}

Objective: Dystrophic aortic insufficiency is characterized by dilation of the aortic annular base and sinotubular
junction diameters preventing coaptation of thin and pliable cusps amenable to valve repair. An expansible aortic
ring was designed to reduce dilated aortic root diameters to increase valvular coaptation height while maintaining
root dynamics. The properties of the device were tested in vitro and in vivo in an ovine model.

\begin{abstract}
Methods: Expansible rings were composed of an elastomer core covered by polyester fabric. After in vitro analysis of their mechanical properties, the rings were implanted in 6 sheep at both the level of the annular base and sinotubular junction (double subvalvular and supravalvular external aortic annuloplasty). Root dynamics were assessed by using intracardiac ultrasonography before surgical intervention and at 6 months. Histologic, scanning electron microscopic, and mechanical studies were then performed on explanted samples.
\end{abstract}

Results: The expansible ring produced a significant reduction of the aortic annular base and sinotubular junction diameters. Coaptation height was increased from $2.5 \pm 0.7 \mathrm{~mm}$ to $6.2 \pm 1.1 \mathrm{~mm}(P<.001)$. Mechanical testing on 6-month explanted samples revealed no significant differences in elastic modulus. Dynamics of the root were well preserved. Histomorphologic studies showed incorporation of the material without degradation.

Conclusions: Expansible aortic ring implantation produces a significant annuloplasty that increases coaptation height while preserving the dynamics of the aortic root. The effectiveness of the device in treating aortic insufficiency is currently being evaluated in the prospective Conservative Aortic Valve surgery for aortic Insufficiency and Aneurysm of the Aortic Root trial comparing conservative aortic valve surgery versus mechanical valve replacement.

Dystrophic aortic insufficiency (AI) is characterized by dilation of both the aortic annular base and sinotubular junction (STJ) diameters preventing coaptation of otherwise thin and pliable cusps that are structurally close to normal. ${ }^{1,2}$ Until recently, valve replacement was the only surgical option. Because of improved understanding of aortic valve dynamics, conservative aortic valve surgery was developed based on reduction of the dilated aortic root diameters (with or without cusp lesion) while preserving root dynamics with vortices (neosinuses of Valsalva) and expansibility (interleaflet triangles). ${ }^{3-5}$

From the INSERM, U 698, Cardiovascular Bioengineering, ${ }^{a}$ Bichat University Hospital, Paris, France; Cardiovascular Surgery, ${ }^{\mathrm{b}}$ Foch Hospital, Suresnes, France; Vascular Surgery, ${ }^{\mathrm{c}}$ Ambroise Paré University Hospital, Boulogne-Billancourt, France; Cardiology, ${ }^{\mathrm{d}}$ Marie Lannelongue Hospital, Le Plessis Robinson, France; CORONEO, Inc, ${ }^{\mathrm{e}}$ Montréal, Québec, Canada; Institut Galilée, ${ }^{\mathrm{f}}$ University Paris 13, Villetaneuse, France; and the University of Orléans, Orléans, ${ }^{\mathrm{g}}$ France.

E. Lansac is the recipient of a "poste d'accueil INSERM." A. Abed was supported by the Agence of Biomedecine. The study was supported by CORONEO, Inc; INSERM; University Paris 13; and Assistance Publique des Hôpitaux de Paris.

Disclosures: Drs Lansac and Di Centa have Consultant Agreements with the company CORONEO, Inc.

Received for publication Feb 23, 2009; revisions received April 13, 2009; accepted for publication May 17, 2009; available ahead of print July 13, 2009.

Address for reprints: Anne Meddahi-Pellé, MD, PhD, INSERM, U 698, Hemostasis, Bio-engineering and Cardiovascular Remodelling, Cardiovascular Bioengineering Team, Bichat University Hospital, 75018 Paris, France (E-mail: anne.pelle@ inserm.fr).

J Thorac Cardiovasc Surg 2009;138:718-24

$0022-5223 / \$ 36.00$

Copyright (c) 2009 by The American Association for Thoracic Surgery

doi:10.1016/j.jtcvs.2009.05.024
Two types of aortic valve-sparing operations were originally performed for the treatment of root aneurysms: remodeling of the aortic root and reimplantation of the aortic valve. ${ }^{6-8}$ The remodeling technique used a scalloped graft to provide a physiologic reconstruction of the root, but it does not address annular base dilation..$^{6-8}$ The reimplantation procedure as an inclusion technique reduces both diameters to the detriment of root dynamics. ${ }^{6}$ We suggested combining the advantages of both approaches by placing an external subvalvular ring annuloplasty associated with the remodeling procedure (aortic root aneurysm; Figure 1, $A$ ) or with an external supravalvular ring annuloplasty to stabilize the STJ (isolated AI; Figure 1, $B)^{2,7,9}$ To standardize this physiologically based approach to conservative aortic valve surgery, we designed a calibrated expansible aortic ring that should reduce dilated diameters in diastole to increase valvular coaptation height while maintaining root systolic expansibility.

The characteristics of this new device were established in vitro on the bench top. Biocompatibility of the ring and the effect of its implantation on root dynamics were studied in vivo in the ovine model.

\section{MATERIALS AND METHODS \\ Ring Fabrication}

Design prerequisites for the ring were (1) target in vivo device expansion of between $5 \%$ and $15 \%$ over the cardiac cycle, (2) minimized radial thickness of the ring while preserving the desired dynamic behavior, (3) ring durability, and (4) stable and predictable bioreaction with surrounding tissues. 


\section{Abbreviations and Acronyms \\ $\mathrm{AI}=$ aortic insufficiency \\ SEM $=$ scanning electron microscopy \\ STJ $=$ sinotubular junction}

The aortic rings (Extra-Aortic; CORONEO, Inc, Montreal, Quebec, Canada) are composed of 2 silicone elastomer cores covered with a polyester textile (Figure 2). Overall, the device measures $3 \mathrm{~mm}$ wide by $5 \mathrm{~mm}$ high. Black indicator marks on the ring and suture windows in the ring holder are incorporated to facilitate optimal suture placement between the 2 cores (Figure 2, $A$ and $B$ ).

\section{Mechanical Testing of the Rings}

Three types of mechanical testing were carried out: ultimate tensile strength, cyclic durability, and mechanical properties of implanted (6 months) and nonimplanted (control) elastomer cores. The objective of the ultimate tensile strength testing was to measure the load and strain at ring rupture to establish an upper limit on increased strains for cyclic durability testing and to determine safety factors for device failure caused by excessive loading or strain after implantation.

Cyclic durability testing was performed to cycle samples of the ring at normal and increased strain ranges with alternating strain of $15 \%$ not only to measure the cycles at failure but also to track the permanent deformation of the device at weekly intervals. Rings were radially expanded with different strain biases. A specialized test apparatus was designed and built by Bodycote Materials Testing (Mississauga, Ontario, Canada) to test these devices at $5 \mathrm{~Hz}$ in a temperature-controlled saline bath.

A tensile tester with custom-designed grips (Quasar 2.5; Galdabini, Cardano al Campo, Italy) was used to compare implanted with nonimplanted elastomer cores to characterize changes in mechanical properties as a result of in vivo device function.

\section{In Vivo Implantation of Expansible Aortic Ring}

Given the anatomy of a normal aortic root in sheep, remodeling associated with a subvalvular ring was not feasible, and the technical choice was made to perform a double subvalvular and supravalvular aortic annuloplasty to evaluate the expansible aortic rings.

Treatment of animals complied with the "Principles of laboratory animal care" formulated by the National Society for Medical Research. Anesthesia was induced with $1.0 \mathrm{mg} / \mathrm{kg}$ intravenous ketamine and $4.0 \mathrm{mg} / \mathrm{kg}$ body weight propofol and was maintained with $1.5 \%$ to $2.5 \%$ endotracheal isoflurane. Analgesia was obtained by using intramuscular administration of $0.2 \mathrm{~mL}$ of nalbuphine before intervention and twice a day until postoperative day 7 or later, if necessary.

An intracardiac ultrasonographic probe (Siemens AcuNav, Berlin, Germany; 5-10 MHz) was introduced through the left internal jugular vein into the right atrium to analyze aortic root parameters (coaptation height, root diameter, expansibility, and compliance). Through a left thoracotomy, 6 adult prealpine sheep underwent a double subvalvular and supravalvular aortic annuloplasty under cardiopulmonary bypass. The aorta was transected $1 \mathrm{~cm}$ above the STJ. External dissection of the root was achieved down to the annular base, attaining the subvalvular plane. Space under the coronaries was cleared because they were not detached from the aortic wall. Five subvalvular $\mathrm{U}$ stitches are placed inside out below the nadir of each cusp and at the base of the interleaflet triangles (except between the right and noncoronary sinuses to avoid injury to the bundle of His) and passed through the open subvalvular ring (inner diameter, $22 \mathrm{~mm}$ ). The ring is passed under the coronary arteries and fastened through pre-established eyelets. $U$ stitches are then tied to maintain the ring at the annular base level. Three supravalvular stitches are passed at each commissural level. The aortotomy is closed, and the commissural stitches are passed through the supravalvular ring (inner diameter, $18 \mathrm{~mm}$ ) and tied at the STJ level.

After recovery, animals were ambulatory on a farm. At 6 months, they underwent intracardiac ultrasonographic evaluation of the aortic root parameters after achievement of general anesthesia. They were thereafter killed with an intravenous bolus of propofol and $20 \mathrm{mEq}$ of potassium chloride. The heart was explanted, rinsed in normal saline, photographed, and transferred to a $10 \%$ formalin solution.

\section{Intracardiac Echocardiographic Acquisition of Aortic Root Parameters}

Aortic root parameters were studied preoperatively and at 6 months postoperatively. Coaptation height was defined as the distance between the lowest and highest points of cusp coaptation. The systolic and

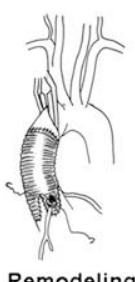

Remodeling

A

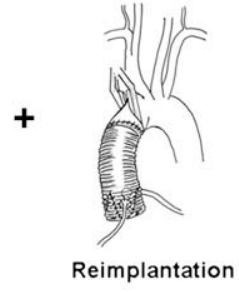

Reimplantation

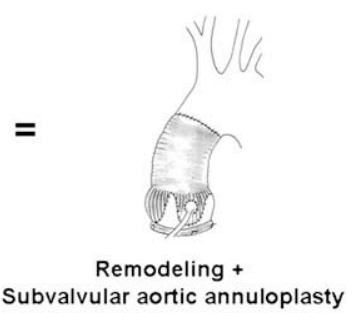

Subvalvular aortic annuloplasty

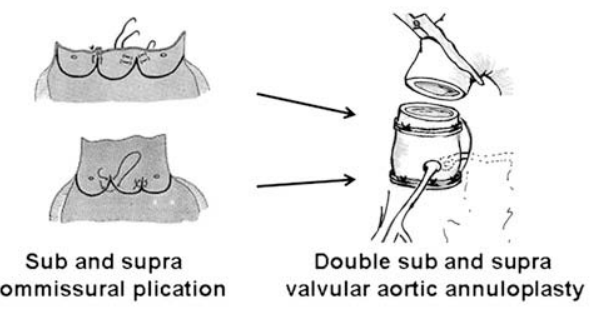

B commissural plication

FIGURE 1. Clinical applications of aortic annuloplasty for conservative aortic valve surgery. A, Remodeling associated with a complete subvalvular aortic ring combining advantages of the original remodeling and reimplantation techniques. B, Double subvalvular and supravalvular external aortic annuloplasty by using open rings, standardizing the principles of the subvalvular and supravalvular plicating stitches. 


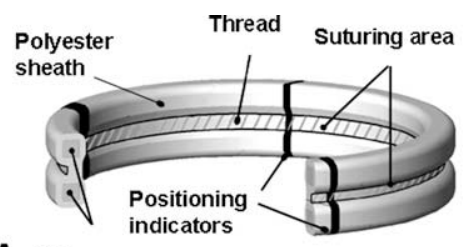

A silicone core
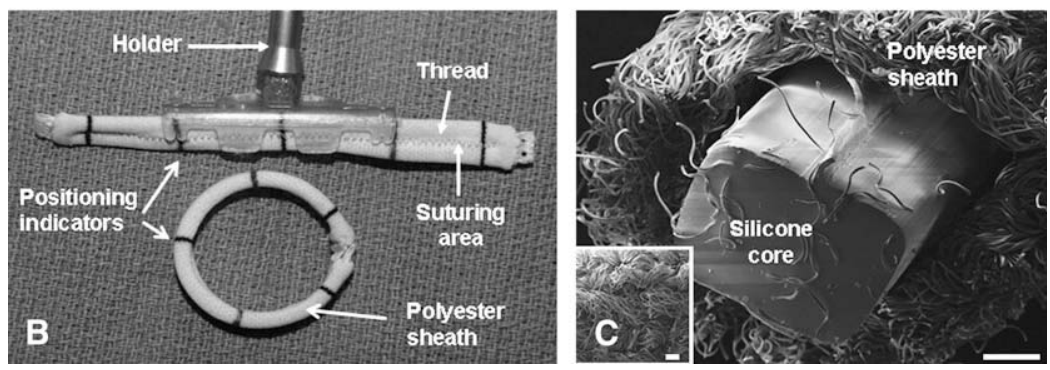

FIGURE 2. Expansible aortic ring before implantation. A, Cut-away schematic diagram of the device showing its key components. B, Top: Before implantation, the ring is opened and mounted on a holder that is attached to the handle. The black indicator marks on the ring facilitate optimal suture placement. Bottom: After implantation, the ends of the ring are fastened. C, Scanning electronic microscope image showing a cross-section of the ring with its rectangular silicone core covered by a polyester sheath (insert). Scale bars $=200 \mu \mathrm{m}$.

diastolic aortic root diameters were measured on a long-axis view (Figure 3): internal aortic annular base diameter and STJ external diameter from leading edge to leading edge. ${ }^{10}$ From these data, root dynamics indices, such as systolic expansion, compliance, and pressure strain elastic modulus, were calculated. ${ }^{11}$

\section{Morphologic and Histologic Analyses of the Explanted Rings}

Rings were excised with $0.5 \mathrm{~cm}$ of surrounding tissue and gently rinsed in saline. Histologic samples were fixed in $4 \%$ paraformaldehyde solution, dehydrated, and embedded in paraffin. Seven-micrometer-thick sections were set on a Leitz Wetzlar microtome (Wetzlar, Germany), stained with hemalun-eosin, and photographed with Q Capture Pro Software (Qimaging, Surrey, British Columbia, Canada).

Ring samples were examined by using scanning electron microscopy (SEM) before and 6 months after implantation. Images were acquired with a LEO S440 SEM (LEO, Cambridge, United Kingdom) set at a beam-accelerating voltage of $15 \mathrm{keV}$.

\section{Statistical Analysis}

Data were analyzed with StatView 4.5 software (Abacus Concepts, Berkley, Calif). Results are presented as means \pm standard deviations. A small sample size $t$ test for difference between means was used for statistical analysis of material degradation results carried out by using mechanical testing. Statistical analysis of echographic results was carried out by using an unpaired 2-tailed $t$ test.

The authors had full access to the data and take responsibility for its integrity. All authors have read and agree with the manuscript as written.

\section{RESULTS}

\section{Expansible Aortic Ring and Mechanical Testing}

Figure 2 shows the characteristics of the expansible annuloplasty ring used in this study. Two silicone cores (Figure 2, $A$ ) are sheathed in a polyester textile (Figure 2, $B$ and $C$ ), which allows sutures to be passed between them.

Mechanical testing was carried out on specimens of silicone elastomer clamped in traditional tensile-testing grips. The elastic modulus of the silicone material was measured over the functional strain range of the device of $5 \%$ to $20 \%$. When silicone rings were mounted on rotary grips and pulled to supraphysiologic levels $(300 \mathrm{~mm} / \mathrm{min})$ until rupture, they failed at a strain of $645 \% \pm 17 \%$.

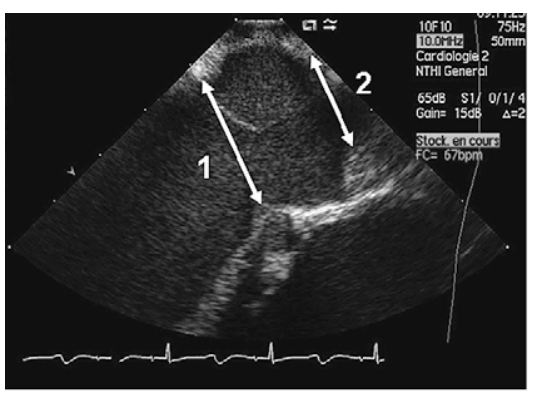

A

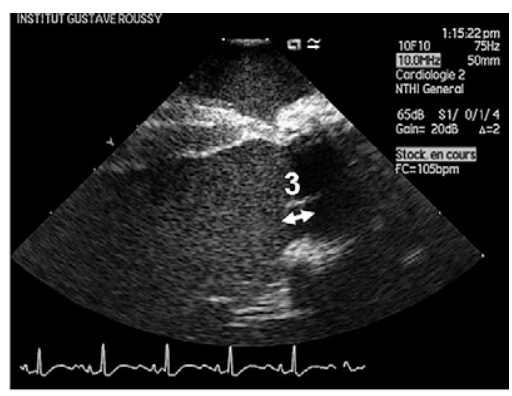

B

FIGURE 3. Intracardiac ultrasonographic aortic root long-axis view: A preoperative; B, 6 months postoperative. 1 , Aortic annular base diameter; 2 , sinotubular junction diameter; 3 , coaptation height. 

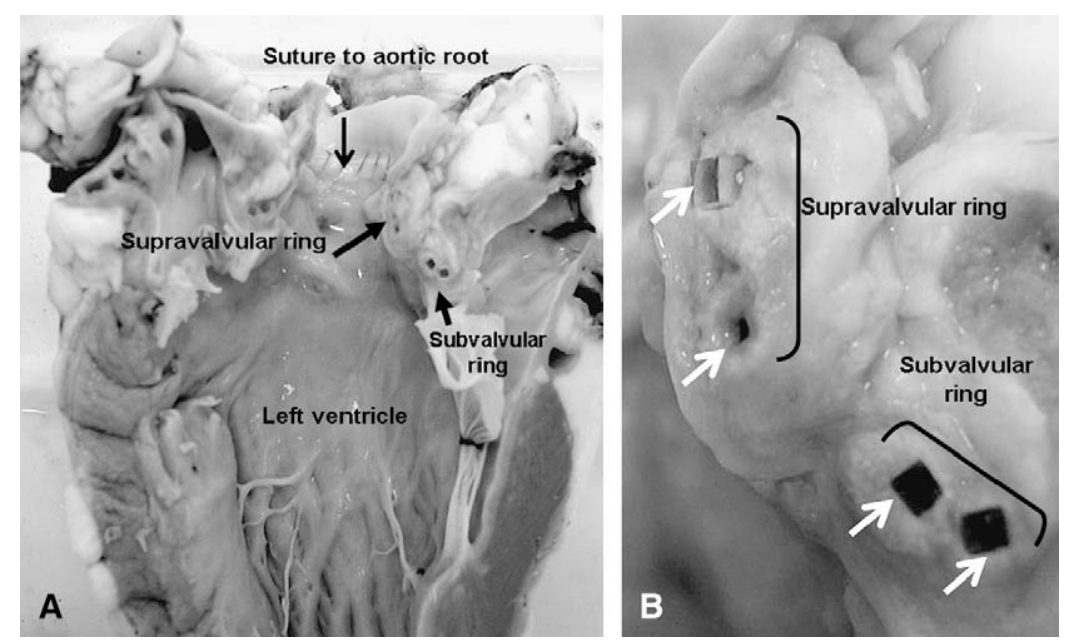

FIGURE 4. Aortic rings at 6 months after implantation. A, Macroscopic aspect of the heart showing the 2 rings. No apparent calcifications were observed. B, Close-up of the implantation site. Arrows indicates the silicone core locations.

After an initial time count of 25.4 million cycles, which represents a sufficient time for bioreaction to occur and stabilize, the seam and thread of the mechanically tested samples showed no rupture or damage. This was also the case with explanted rings that were exposed to a comparable cycle count in vivo.

\section{In Vivo Device Function}

Expansible rings were successfully implanted in 6 sheep (Figure 4, A). The mean crossclamp time and pump time were $53.3 \pm 5.0$ and $90.0 \pm 9.9$ minutes, respectively. Postoperative course was uneventful in all but 1 sheep, which had a fever. At death at 6 months, it had endocarditis with cusp perforation and periannular abscess. Bacteriologic analysis showed Staphylococcus species bacteria, probably because of perioperative contamination.

Intracardiac ultrasonographic analysis allowed visualization of valvular coaptation and aortic root parameters in all cases (Table 1). Prosthetic rings created a significant reduction of the aortic annular base and STJ diameters without significant transvalvular gradient (mean, $3.4 \pm 2.1 \mathrm{~mm} \mathrm{Hg}$ ). Subvalvular and supravalvular annuloplasty increased coaptation height from $2.5 \pm 0.7$ to $6.2 \pm 1.1 \mathrm{~mm}$ at 6 months $(P<.001)$. Dynamics of the root (compliance, expansibility, and elastic modulus) were preserved 6 months after rings implantation, with aortic annular base and STJ systolic expansions of $12.3 \% \pm 2.9 \%$ and $10.0 \% \pm 3.2 \%$, respectively (Table 1 ).

Although the calculated compliance appears to increase at the annulus level after 6 months, the difference between preoperative and 6-month compliance is not statistically significant.

\section{Gross Examination and Histologic Examination}

The device was clearly visible in explanted hearts at 6 months (Figure 4). There was no erosion of the external ring into the aorta or adjacent structures at the level of the aortic annular base or at the STJ level. Coronary arteries were patent in all cases. Aortic cusps remained thin and pliable, except for 1 sheep (endocarditis). Macroscopic examination of the hearts did not show calcification (Figure 4), as confirmed by means of Alizarin red staining (not shown). The polyester fabric was fully integrated in the tissue (Figure 4, $B$ ) and colonized by a dense extracellular matrix (Figure 5). Low (Figure 5, A) and high (Figure 5,C) magnifications of the samples showed the encapsulation of the elastomer core in a fibrous zone (Figure 5,D). No inflammatory reaction was noted around the device, and no apparent degradation of the elastomer core was observed by means of SEM observation (Figure 5, $B$ ).

\section{Material Testing After Implantation}

Differences in tensile testing results measured before and after implantation are reported in Table 2. Differences in effective Young's modulus measured between control

TABLE 1. Intracardiac ultrasonographic measurements of aortic root diameters preoperatively and at 6 months in sheep $(n=6)$

\begin{tabular}{lccccc}
\hline & \multicolumn{2}{c}{ Aortic annular base } & & \multicolumn{2}{c}{ Sinotubular junction } \\
\cline { 2 - 3 } & Preop & Postop & & Preop & Postop \\
\hline $\begin{array}{c}\text { Systolic diameter } \\
(\mathrm{mm})\end{array}$ & $21.3 \pm 1.8$ & $17.7 \pm 2.5^{*}$ & $22.3 \pm 1.8$ & $14.6 \pm 1.1^{*}$ \\
$\begin{array}{c}\text { Diastolic diameter } \\
(\mathrm{mm})\end{array}$ & $19.7 \pm 1.5$ & $15.8 \pm 2.5^{*}$ & $20.8 \pm 2.1$ & $13.3 \pm 1.0^{*}$ \\
$\begin{array}{c}\text { Systolic expansion } \\
(\%)\end{array}$ & $8.0 \pm 1.5$ & $12.3 \pm 2.9$ & $7.6 \pm 2.7$ & $10.0 \pm 3.2$ \\
$\begin{array}{c}\text { Compliance } \\
\left(10^{-1} \mu \mathrm{m} / \mathrm{Pa}\right)\end{array}$ & $8.1 \pm 2.8$ & $11.2 \pm 2.7$ & $7.8 \pm 3.2$ & $7.7 \pm 2.2$ \\
$\mathrm{E}_{\mathrm{p}}\left(10^{5} \mathrm{~Pa}\right)$ & $0.26 \pm 0.07$ & $0.15 \pm 0.05$ & $0.30 \pm 0.12$ & $0.19 \pm 0.07$ \\
\hline
\end{tabular}

Preop, Preoperatively; Postop, 6 months postoperatively; $E_{p}$, pressure strain elastic modulus. *Comparison between the Pre-op and Post-op groups, $P<.001$. 

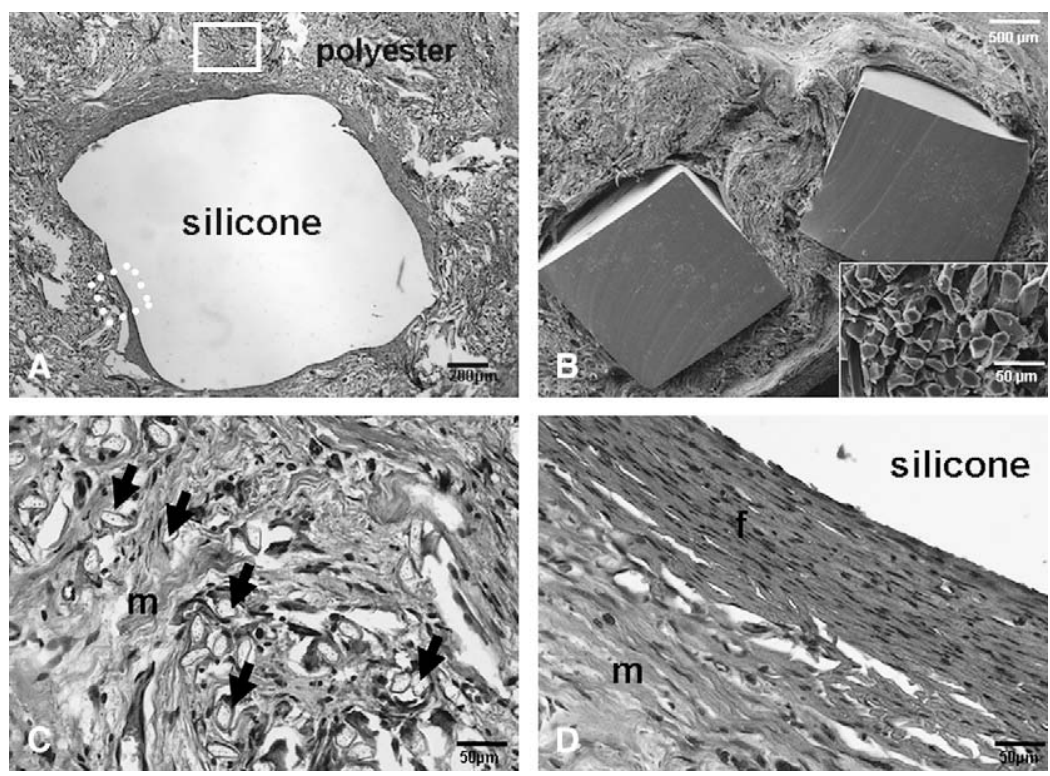

FIGURE 5. Histologic sections of the aortic ring 6 months after implantation. A, The silicone core was embedded in a fibrous area surrounded by polyester sheath included in the extracellular matrix. B, Scanning electron microscope image of the expansible ring 6 months after implantation. The ring is integrated in the extracellular matrix and embedded the silicone core. The insert shows a higher magnification of the polyester fibers. C, Close-up of polyester fibers (white rectangle in $\mathrm{A}$; black arrows). D, Close-up of the fibrous area surrounding the silicone core (dotted square in A). Hematoxylin and eosin staining: $m$, matrix; $f$, fibrous zone.

nonimplanted samples and the 6-month explanted samples from the annular position over the operating range of the device were not statistically significant $(P>.05)$. In all cases the Young's moduli of samples were measured to be within the acceptable operating range of the device.

\section{DISCUSSION}

The aortic root is a dynamic complex that includes the cusps, the crown-shaped aortic annulus, the interleaflet triangles, and the sinuses of Valsalva. Systolic expansion of the aortic root through the interleaflet triangles $(5 \%$ to $15 \%$ at the aortic annular base and STJ junction levels) maximizes ejection and reduces shear stress on the cusps. ${ }^{3,5,12}$

From experience with mitral valve repair, reconstructive methods have been developed to treat AI based on native aortic valve preservation or repair while replacing or stabilizing the other components of the aortic root. ${ }^{1,2,6,8,13}$ Basic principles for conservative aortic valve surgery associate treatment of the dilated aortic annular base and STJ diameters (with or without cusp lesion) and preservation of root dynamics with vortices and expansibility. ${ }^{1,2,9}$

Reduction of dilated aortic root diameters was first attempted by Taylor and colleagues ${ }^{14}$ in 1958 , who performed, on a beating heart, a subvalvular aortic annuloplasty so-called aortic circumclusion with an external circumferential suture around the aortic annular base. Cabrol and associates ${ }^{15}$ later described a subvalvular and supravalvular annuloplasty with placement of commissural plicating stitches, which are still currently used. However, this technique remains an incomplete annulo- plasty, which also plicates the interleaflet triangles, impairing valve dynamics. ${ }^{9,15}$ More recently, the remodeling of the aortic root described by Yacoub and coworkers ${ }^{8}$ and the reimplantation of the aortic valve described by David and colleagues ${ }^{6}$ provide a supravalvular annuloplasty by reducing the STJ diameter. The remodeling does not address annular base dilation, whereas the reimplantation provides a subvalvular annuloplasty to the detriment of root dynamics. Indeed, cusp motion and flow patterns across the reconstructed aortic root are more physiologic (1) after remodeling of the aortic root than after reimplantation of the aortic valve and (2) after procedures using a prosthetic conduit fashioned with neosinuses of Valsalva than without. ${ }^{16,17}$

Based on these findings, we propose, depending on the phenotype of the dystrophic aortic root, to associate a subvalvular annuloplasty ring to the remodeling technique in case of aortic root aneurysm or to a supravavular ring

TABLE 2. Differences in Young's modulus measured between control samples and 6-month explanted samples from the annular position over the operating range of the device

\begin{tabular}{lccc}
\hline & \multicolumn{3}{c}{ Young's modulus } \\
\cline { 2 - 4 } Strain range & $\mathbf{5 \%}$ to $\mathbf{1 0} \%$ & $\mathbf{1 0} \%$ to $\mathbf{1 5} \%$ & $\mathbf{1 5} \%$ to $\mathbf{2 0} \%$ \\
\hline $\begin{array}{l}\text { Percentage difference in } \\
\text { Young's modulus } \\
\text { between control and } \\
\text { explanted samples }\end{array}$ & -7.1 & -7.8 & -9.8 \\
$P$ value & & & \\
\hline
\end{tabular}


(double subvalvular and supravalvular snnuloplasty) in case of isolated AI (sinus of Valsalva $<40 \mathrm{~mm}$; Figure 1), ${ }^{2,7,9}$ the subvalvular annuloplasty is associated with a second supravalvular ring, thus achieving a double-ring annuloplasty. The clinical effectiveness of this physiologic approach to conservative aortic valve surgery was confirmed in a preliminary trial (96 patients) using rings obtained from a slice of a Dacron tube graft. ${ }^{2,7,9}$ Choice of the external ring was standardized and based on the sole measurement of internal aortic annular base diameter with Hegar dilators. In case of AI of grade 2 or greater, aortic rings were undersized.

To address the need for a dedicated aortic annuloplasty device, we designed a new expansible aortic ring that provides a complete and calibrated annuloplasty while preserving root expansibility.

Previous aortic annuloplasty techniques were described. Internal annuloplasty was proposed by using either a circular suture, ${ }^{18}$ glutaraldehyde-tanned pericardial strips, or a subvalvular Gore-Tex band (W. L. Gore \& Associates, Inc, Newark, Del). ${ }^{19}$ Hahm and coworkers ${ }^{20}$ described an internal prosthetic ring at the STJ associated with a strip along the fibrous annulus. Other experimental devices, such as 3-dimensional internal rings ${ }^{21,22}$ or external adjustable nylon bands, ${ }^{23}$ were developed in animal models but never implanted in human subjects.

The advantages of a compliant ring as opposed to a noncompliant ring are (1) an increase in valve triangulation that leads to reduced leaflet stresses and superior flow characteristics and (2) superior mobility and reduced stress on surrounding structures (interleaflet triangles, mitral valve annulus, and left ventricular outflow tract tissue) during the cardiac cycle, leading to a closer approximation of physiologic aortic root dynamics. The ring is placed externally, thus preventing complications linked to endovascular prosthesis, such as hemolytic or thromboembolic events. Moreover, the external placement of the ring avoids placing tension on the device's fixation stitches by the expanding aorta.

The primary elastic element of the device is its silicone elastomer. A design target for in vivo device expansion was set between $5 \%$ and $15 \%$ over the cardiac cycle. The overall device compliance is dictated by elastomer core material and cross-section, as well as the mechanical properties of the polyester fabric, the seam, and friction between device components. The elastomer material is an implantable-grade 2-part silicone. ${ }^{24}$ It is durable and has a high tear strength and elongation to failure. Elastomer component dimensions were designed for optimal ring dynamics in a low-profile configuration while meeting durability requirements because as the device cross-sectional area decreases, stresses would be seen to increase over the same strain range. The polyester was selected from validated implantable textiles because of its suitable mechanical properties and ability to sustain an appropriate degree of tissue ingrowth. ${ }^{25}$
The expansible aortic ring was implanted in an orthotopic position, allowing precise analysis of its effect on valvular coaptation and root dynamics. After 6 months of implantation in an ovine model, aortic root diameters were significantly reduced, ensuring a $130 \%$ increase of valvular coaptation height. Systolic expansion at the annular base and STJ diameters were preserved within the design target of $5 \%$ to $15 \%$.

Histology results obtained at 6 months corresponded to typical remodeling processes showing polyester tissue integration and a fibrotic ring encapsulation. No adverse inflammatory reaction was observed. Based on macroscopic observations of silicone cores, SEM examination, and functional and mechanical studies, no evidence of damage to the silicone component was found.

This investigation represents a feasibility and safety study of the device, with the main limitation being device implantation in a healthy animal model. However, no experimental models of chronic AI or aortic root aneurysm are currently available.

Effectiveness of this expansible aortic ring will be assessed in the ongoing prospective multicenter Conservative Aortic Valve surgery for aortic Insufficiency and Aneurysm of the Aortic Root (CAVIAAR) trial, which compares conservative aortic valve surgery with mechanical replacement. ${ }^{9}$ Patients with aortic root aneurysms will undergo the remodeling of the aortic root associated with an expansible subvalvular annuloplasty. Double subvalvular and supravalvular expansible annuloplasty will be performed for patients with isolated dystrophic AI. Expanding indications of aortic valve sparing and repair emphasize the need for dedicated devices that standardize the technique and expand use of the procedure. Devices that preserve the natural dynamics of the root might improve the long-term durability of conservative aortic valve surgery.

We thank the Ecole de Chirurgie de l'Assistance Publique Hôpitaux de Paris (Paris, France) for the use of its surgical structures and animal facilities; G. Moulin, N. Leveque, and V. Ganachaud for their effort and support, which were essential to the completion of these experiments; and P. Portes (LIMHP, CNRS, Villetaneuse) for his help in SEM experiments.

\section{References}

1. ElKhoury G, Glineur D, Rubay J, Verhelst R, d'Acoz Y, Poncelet A, et al. Functional classification of aortic root/valve abnormalities and their correlation with etiologies and surgical procedures. Curr Opin Cardiol. 2005;20:115-21.

2. Lansac E, Di Centa I, Raoux F, Attar NA, Acar C, Joudinaud T, et al. A lesional classification to standardize surgical management of aortic insufficiency towards valve repair. Eur J Cardiothorac Surg. 2008;33:872-8.

3. Dagum P, Green GR, Nistal FJ, Daughters GT, Timek TA, Foppiano LE, et al. Deformational dynamics of the aortic root: modes and physiologic determinants. Circulation. 1999;100(suppl):II54-62.

4. Lansac E, Lim HS, Shomura Y, Lim KH, Rice NT, Goetz W, et al. A four-dimensional study of the aortic root dynamics. Eur J Cardiothorac Surg. 2002;22:497-503.

5. Thubrikar M, Bosher LP, Nolan SP. The mechanism of opening of the aortic valve. J Thorac Cardiovasc Surg. 1979;77:863-70. 
6. David TE, Feindel CM. An aortic valve-sparing operation for patients with aortic incompetence and aneurysm of the ascending aorta. $J$ Thorac Cardiovasc Surg. 1992;103:617-22.

7. Lansac E, Di Centa I, Bonnet N, Leprince P, Rama A, Acar C, et al. Aortic prosthetic ring annuloplasty: a useful adjunct to a standardized aortic valve-sparing procedure? Eur J Cardiothorac Surg. 2006;29:537-44.

8. Yacoub M, Fagan A, Stassano P, Radley-smith R. Result of valve conserving operations for aortic regurgitation. Circulation. 1983;68(suppl III):321.

9. Lansac E, Di Centa I. From dynamic anatomy to aortic annuloplasty: the tale of the ring. In Sakalihasan N, Kuivaniemi H, Michel JB, eds. Aortic aneurysms: new insights into an old problem. Liege, Belgium: Liege University Press; 2008;199-233.

10. Roman MJ, Devereux RB, Niles NW, Hochreiter C, Kligfield P, Sato N, et al. Aortic root dilatation as a cause of isolated, severe aortic regurgitation. Prevalence, clinical and echocardiographic patterns, and relation to left ventricular hypertrophy and function. Ann Intern Med. 1987;106:800-7.

11. Long A, Rouet L, Vitry F, Albertini JN, Marcus C, Clement C. Compliance of abdominal aortic aneurysms before and after stenting with tissue Doppler imaging: evolution during follow-up and correlation with aneurysm diameter. Ann Vasc Surg. 2009;23:49-59.

12. Sutton JP 3rd, Ho SY, Anderson RH. The forgotten interleaflet triangles: a review of the surgical anatomy of the aortic valve. Ann Thorac Surg. 1995;59:419-27.

13. Carpentier A. Cardiac valve surgery - "the French correction." J Thorac Cardiovasc Surg. 1983;86:323-37.

14. Taylor WJ, Thrower WB, Black H, Harken DE. The surgical correction of aortic insufficiency by circumclusion. J Thorac Surg. 1958;35:192-205.

15. Cabrol C, Cabrol A, Guiraudon G, Bertrand M. [Treatment of aortic insufficiency by means of aortic annuloplasty]. Arch Mal Coeur Vaiss. 1966;59:1305-12.
16. Fries R, Graeter T, Aicher D, Reul H, Schmitz C, Bohm M, et al. In vitro comparison of aortic valve movement after valve-preserving aortic replacement. J Thorac Cardiovasc Surg. 2006;132:32-7.

17. De Paulis R, De Matteis GM, Nardi P, Scaffa R, Buratta MM, Chiariello L. Opening and closing characteristics of the aortic valve after valve-sparing procedures using a new aortic root conduit. Ann Thorac Surg. 2001;72:487-94.

18. Haydar HS, He GW, Hovaguimian H, McIrvin DM, King DH, Starr A. Valve repair for aortic insufficiency: surgical classification and techniques. Eur J Cardiothorac Surg. 1997;11:258-65.

19. Izumoto H, Kawazoe K, Kawase T, Kim H. Subvalvular circular annuloplasty as a component of aortic valve repair. J Heart Valve Dis. 2002;11:383-5.

20. Hahm SY, Choo SJ, Lee JW, Seo JB, Lim TH, Song JK, et al. Novel technique of aortic valvuloplasty. Eur J Cardiothorac Surg. 2006;29:530-6.

21. Duran CM, Gallo R, Prabhakar G, Kumar N, Hainau B. New prosthetic ring for aortic valve annuloplasty. Cardiovasc Surg. 1993;1:166-71.

22. Reimold SC, Aranki SF, Caguioa ES, Solomon SD, Birjiniuk V, Cohn LH, et al. An external aortic root device for decreasing aortic regurgitation: in vitro and in vivo animal studies. J Card Surg. 1994;9:304-13.

23. Gogbashian A, Ghanta RK, Umakanthan R, Rangaraj AT, Laurence RG, Fox JA, et al. Correction of aortic insufficiency with an external adjustable prosthetic aortic ring. Ann Thorac Surg. 2007;84:1001-5.

24. Chauvel-Lebret DJ, Pellen-Mussi P, Auroy P, Bonnaure-Mallet M. Evaluation of the in vitro biocompatibility of various elastomers. Biomaterials. 1999;20: 291-9.

25. Abed A, Deval B, Assoul N, Bataille I, Portes P, Louedec L, et al. A biocompatible polysaccharide hydrogel-embedded polypropylene mesh for enhanced tissue integration in rats. Tissue Eng. 2008;14:519-27. 